\title{
SURAMÉRICA Y LOS REFUGIADOS COLOMBIANOS
}

\author{
Diana Ortiz* \\ Sergio Kaminker**
}

\begin{abstract}
Guerra y política, orden y violencia, violencia y democracia, y en el límite, vida y muerte, son algunas de las múltiples oposiciones y complementariedades a partir de las cuales se hace descifrable la historia colombiana (Sánchez, Gonzalo)'.
\end{abstract}

A treinta años de la Declaración de Cartagena en una región que es considerada en el mundo región de paz, el acontecer cotidiano muestra otra realidad. En Colombia un país democrático, ubicado en el noroccidente de Sur América, la guerra interna ha traspasado las fronteras nacionales y la violencia estatal se asemeja a la aplicada por los gobiernos militares en el Cono Sur. Dan cuenta de ello, entre otros registros de violación masiva y sistemática de los derechos humanos, más de cinco millones de desplazados forzados internos y cerca de medio millón de refugiados. El destierro utilizado como mecanismo de exclusión política, se empieza a visibilizar por la magnitud del éxodo. La reconstrucción del discurso que los niega da cuenta de que no sólo esconden u obliteran relaciones de dominación, sino que también las construyen, las reproducen y las materializan. ¿Quiénes son esos refugiados? ¿A dónde se dirigen en busca de protección? ¿Cuál es el lugar que les confiere los países que los protegen? Son algunas de las preguntas que se abordan en el presente artículo.

Palabras claves: derechos humanos, desplazamiento forzado interno, refugio, Colombia, Suramérica.

* Grupo de Investigación en Movilidad Humana (Colombia). Doctoranda en Ciencias Sociales del Instituto de Desarrollo Económico y Social IDES. Buenos Aires/Argentina.

** Centro Nacional Patagónico - CONICET, Puerto Madryn, Argentina. Doctorando en Ciencias Sociales de la Universidad Nacional de San Martín. Buenos Aires/Argentina.

${ }^{1}$ SÁNCHEZ, Gonzalo. Guerra y política en la sociedad colombiana. Bogotá: Ed. Nomos, p. 8. 


\section{Introducción}

En noviembre de 1984, el Coloquio Sobre la Protección Internacional de los Refugiados en América Central, México y Panamá: “Problemas Jurídicos y Humanitarios", celebrado en la ciudad colombiana de Cartagena, dejó constancia de "su reconocimiento a la generosa tradición de asilo y refugio practicada por el pueblo y las autoridades de Colombia" ${ }^{2}$. Treinta años después, la región retribuye la generosidad ofreciendo protección y refugio a cientos de miles de colombianos víctimas del conflicto interno de más de medio siglo que vive este país latinoamericano, donde el dolor y la barbarie de la guerra nutren un extenso registro de violación sistemática de derechos humanos.

La historiografía ubica el asesinato de Jorge Eliecer Gaitán, en abril de 1948, como detonante del actual conflicto sociopolítico en Colombia, hecho que dio inició al periodo conocido como La Violencia. Durante esta etapa surgieron las guerrillas liberales, que posteriormente aliadas con grupos de autodefensas campesinas comunistas darían origen a las Fuerzas Armadas Revolucionarias de Colombia (FARC) en 1964, y los grupos paramilitares alentados por el conservadurismo. Estos últimos impulsan, en 1957, el acuerdo bipartidista Frente Nacional que establecía la alternancia en el poder de los dos partidos tradicionales, Liberal y Conservador ${ }^{3}$.

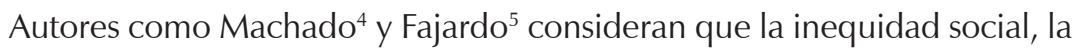
exclusión política y el problema agrario no resuelto son causas estructurales del conflicto interno colombiano. Se estima que, hacia la mitad del siglo pasado, el $70 \%$ de la población colombiana habitaba el campo; La Violencia ocasionó un éxodo masivo de una magnitud tal que la distribución de la población por área - rural y urbana - se invirtió en un período no mayor a diez años ${ }^{6}$.

2 ACNUR. Declaración de Cartagena. In Las nuevas dimensiones de necesidad de protección del ser humano en el inicio del siglo XXI. San José de Costa Rica, 2002, p. 173.

3 PALACIOS, Marco. A la sombra de la Violencia. In Entre la Legitimidad y la Violencia. Colombia 1875-1994. Bogotá: Editorial Normal, 1995, p. 189-238; AYALA, Cesar Augusto. Resistencia y oposición al establecimiento del Frente Nacional. Bogotá: Universidad Nacional de Colombia, 1989; TIRADO MEJÍA, Álvaro. Del Frente Nacional al momento actual: Diagnóstico de una crisis. In Nueva historia de Colombia. Volumen II, Bogotá: Editorial Planeta, 1989.

4 MACHADO, Absalón. De la estructura agraria al sistema agroindustrial. Bogotá: Universidad Nacional de Colombia, Colección Sede, 2002.

5 FAJARDO, Darío. Tierras, poder político y reformas agraria y rural. Ponencia presentada en el Seminario permanente sobre problemas agrarios y rurales: Proyecto «Viabilidad y reconstrucción de la sociedad rural colombiana». Bogotá, 2001.

6 MACHADO, Absalón. La cuestión agraria en Colombia a finales del milenio. In Desplazamiento forzado: Dinámicas de guerra, exclusión y desarraigo. Bogotá: ACNUR, Universidad Nacional de Colombia, 1998. 
Machado $^{7}$, Fajardo $^{8}$, Bello $^{9}$, Meertens $^{10}$, Castillejo $^{11}$ y Pecaute $^{12}$, entre otros, analizan las dinámicas e impactos psicosociales, políticos y culturales, así como las causas coyunturales y estructurales del desplazamiento forzado interno. Existe una vasta producción académica sobre el tema.

Sin embargo, no ocurre lo mismo con el fenómeno del refugio de colombianos. Hay varias causas que pueden haber derivado en esta suerte de omisión académica, pero en particular, parecería haber operado una invisibilización del refugio masivo de colombianos derivada del hecho de que la expulsión se da bajo un régimen democrático que negó, sucesivamente y durante largos períodos, el carácter político del conflicto. Así, durante lo trascurrido del siglo XXI, el estudio de la migración forzada se ha desarrollado dentro de las investigaciones del pasado reciente, considerando que las prácticas represivas utilizadas por los gobiernos autoritarios de las dictaduras habían sido abandonadas.

Este trabajo busca ofrecer una aproximación al estudio sobre el refugio de colombianos en los últimos treinta años y se presenta en dos partes. La primera parte presenta una breve reseña de los momentos coyunturales que muestran un aumento o pico del flujo de refugiados y permite establecer cómo las prácticas de represión y exclusión política utilizadas en la región por las dictaduras militares no fueron de su uso exclusivo ni son asunto del pasado. En la segunda parte se hace referencia a las dinámicas migratorias que muestran en el nuevo siglo un incremento sostenido del refugio e incluye a los países suramericanos como lugares de acogida. Finalmente, se presenta algunas reflexiones sobre lo que implica el refugio para estos latinoamericanos y la región.

\section{Un contexto obligado. Las prácticas represivas entre 1984-2014 y el éxodo de colombianos, en búsqueda de refugio}

Con dos siglos de existencia, las repúblicas latinoamericanas han registrado en su historia reciente múltiples dictaduras militares en medio de su proceso de

MACHADO, De la estructura agraria... op. cit.

8 FAJARDO, Darío. El conflicto armado y su proyección en el campo. In Guerra, sociedad y medio ambiente. Bogotá: FESCOL- Universidad de los Andes, 2004, p. 67-103.

9 BELLO, Martha. El desplazamiento forzado en Colombia: acumulación de capital y exclusión. In Desplazamiento forzado: Dinámicas de guerra, exclusión y desarraigo. Bogotá: ACNUR, Universidad Nacional de Colombia, 2004.

${ }^{10}$ MEERTENS, Donny. El futuro nostálgico: desplazamiento, terror y género. In Desplazamiento forzado: Dinámicas de guerra, exclusión y desarraigo. Bogotá: ACNUR, Universidad Nacional de Colombia, 2004.

${ }^{11}$ CASTILLEJO, Alejandro. Poética de lo otro. Antropología de la guerra, la soledad y el exilio interno en Colombia. Bogotá: Instituto Colombiano de Antropología ICANH, 2001.

12 PÉCAUT, Daniel. La pérdida de los derechos, del significado de la experiencia y de la inserción social. A propósito de los desplazados en Colombia. Rev. Estudios Políticos, n. 14, Medellín, 1999. 
construcción como naciones. Los regímenes dictatoriales que se impusieron en los países de América Latina en la segunda mitad del siglo pasado se enmarcan en el período que las ciencias sociales, y en particular los estudios sobre memoria, han denominado el pasado reciente, que significa inconcluso, abierto, cuya historia aún puede ser reconstruida a partir de sus propios protagonistas. Uno de los ejes de este campo de investigación ha sido la construcción del relato sobre la violación sistemática de los derechos humanos por los gobiernos militares, en el marco de la persecución desatada, bajo la Doctrina de Seguridad Nacional ${ }^{13}$, contra diversos grupos y sectores sociales.

Hace aproximadamente treinta años, la región Suramericana iniciaba el retorno a la democracia. Las sangrientas dictaduras militares que la cercenaron, particularmente en el Cono Sur, llegaban a su fin. Sobre el tema existe gran producción académica, donde los derechos humanos ocupan un lugar preponderante. En la última década, la migración forzada en contexto de baja institucionalidad democrática se ha constituido en un tema de estudio ${ }^{14}$; la mayoría de las investigaciones hacen referencia a los exilios en dictadura.

Mientras que en gran parte de Sudamérica se daba inició a registros sobre masivas violaciones sistemáticas de los derechos humanos ocurridas en los años previos, Colombia, la democracia más sólida y antigua de la región, se abocaba a evitar que las prácticas represivas, en magnitud y forma, fueran un asunto del pasado.

Con respecto a la migración forzada es posible identificar tres momentos o fases en las que la violencia política ha generado la salida masiva de colombianos en los últimos treinta años. En un primer momento, 1984-1995, la represión tendría como objetivo el aniquilamiento de las organizaciones políticas alternativas surgidas en el marco de los diálogos de paz de mediados de los ochenta. En este período la lucha contrainsurgente englobaría el accionar de las fuerzas armadas. El segundo momento, 1996-2005, se caracterizaría por el despoblamiento y repoblamiento de las zonas consideradas de influencia guerrillera, a lo que se sumaría dos factores que complejizan el conflicto interno: la expansión del paramilitarismo y el fenómeno del narcotráfico. Durante los años noventa, la lucha contrainsurgente quedará velada por la "guerra contra el narcotráfico". El tercer momento, desde 2006 hasta la actualidad, se evidencia

${ }^{13}$ La Doctrina de Seguridad Nacional fue una política de defensa norteamericana para América Latina que se inició en la década de los 60 en el contexto de la guerra fría. En su interés por detener la "avanzada del comunismo", Estados Unidos trazó una serie de leyes de "Seguridad Nacional" que se fueron adaptando en cada uno de los países latinoamericanos. Desde esta visión dicotómica del mundo, las Fuerzas Armadas trazaron toda una estrategia para contrarrestar el comunismo considerado en ese momento el "enemigo interno".

${ }^{14}$ RONIGER, Luis. Exilio, ciudadanía y teoría socio-política. 
la consolidación del paramilitarismo como fuerza política y la persecución sistemática a defensores de derechos humanos y a los críticos de la política de guerra total. En este período se hablará de "guerra contra el terrorismo".

En 1984, durante el gobierno de Belisario Betancur (1982-1986), se instala la primera mesa de diálogos con las distintas fuerzas insurgentes del país, unidas en torno a la Coordinadora Guerrillera Simón Bolívar. Uno de los puntos discutidos en la mesa correspondía a la participación política, a partir del cual surge la propuesta de la constitución de movimientos amplios que darían el tránsito a las organizaciones guerrilleras a la legalidad. Entre los nacientes movimientos se encontraban el Frente Popular, A Luchar y la Unión Patriótica (UP). Bajo la Doctrina de Seguridad Nacional estos movimientos fueron declarados "enemigos internos". La Unión Patriótica se constituyó en el caso más emblemático.

La UP fue el único de los movimientos amplios que se constituyó en partido político y que obtiene representatividad por elección popular en órganos del gobierno ${ }^{15}$; la magnitud y el impacto de la acción represiva cometida contra sus miembros ${ }^{16}$ fue tal que en el 2012 fue declarada víctima de genocidio político $^{17}$. Ubicada en el lugar político del oponente, la UP es sometida a la estigmatización y exclusión para ser llevada al aislamiento ${ }^{18}$.

El período comprendido en 1985-1995 se caracterizó por el asesinato selectivo, la desaparición forzada y la masacre en zonas consideradas de influencia ${ }^{19}$ guerrillera. Sánchez ${ }^{20}$ afirma que las masacres ocurridas durante 1988, pusieron al descubierto las dinámicas similares de violencia colectiva contra la izquierda en todo el país y que "esos sucesivos episodios sangrientos alertaron sobre la rápida posibilidad de expansión de la masacre como modalidad de violencia generalizada", sin embargo las autoridades "[l]imitaron su papel a convidados de piedra", dejando "el campo abierto en los años siguientes a una reproducción ampliada de la violencia" teniendo como "su expresión más notoria, aunque no la única, en lo que se ha denominado el genocidio de la Unión

\footnotetext{
15 Entre las elecciones de 1986 y 1988 aumentó en un 22,4\% el número de representantes legislativos obteniendo 103 alcaldías (95 en coalición), 21 diputados y 368 concejales.

${ }_{16} \mathrm{Al}$ inicio de la década de 1990, la UP ya tenía un saldo de 102 parlamentarios asesinados.

17 Se puede consultar los apartados 363 y 372 (pp. 163) de la sentencia condenatoria contra el exjefe paramilitar Hébert Veloza García, alias "HH", del Tribunal Supremo de Bogotá.

${ }^{18}$ ORTIZ, Iván. El genocidio de la Unión Patriótica. Bogotá: Universidad Nacional de Colombia, 2006.

${ }^{19}$ El Centro de Memoria Histórica reportó 1.921 masacres en el período 1985-2012 con 11.751 personas asesinadas.

20 SÁNCHEZ, Gonzalo. Prólogo. Silenciar la democracia. Las masacres de Remedios y Segovia 19821997. En Grupo de Memoria Histórica de la Comisión Nacional de Reparación y Reconciliación (GMH-CNRR), Bogotá: Ed. Taurus-Semana-GMH-CNRR, 2010, p. 17-18.
} 
Patriótica" ${ }^{\prime 21}$. Durante esta época se revive el estado de sitio $^{22}$ constituyéndose, en palabras de Barreto $^{23}$, en una impronta adversa a la vida cotidiana del país.

El desplazamiento forzado interno pasó a ser el protagonista de las dinámicas de la guerra (1996-2005). La masacre instalada como mecanismo de coerción llevó en este período a que cerca de cuatro millones de campesinos huyeran de sus territorios para salvar su vida. La Unidad para la Atención y Reparación Integral a las Victimas de la Presidencia de la República registra 5.975 .057 personas desplazadas forzadamente entre 1985-2014. De acuerdo a la periodización propuesta, el 5\% de los desplazamientos forzados ocurrieron entre 1985-1995 y el $58 \%$ en el período 1996-2005. El Alto Comisionado de las Naciones Unidas para los Refugiados ubicó a Colombia en el 2012 como el país con mayor número de desplazados forzados internos a nivel mundial ${ }^{24}$. Cerca del $14,5 \%$ de la población colombiana se encuentran en situación de desplazamiento forzado interno.

Gráfica 1. Desplazados internos forzados. Colombia 1985-2014*

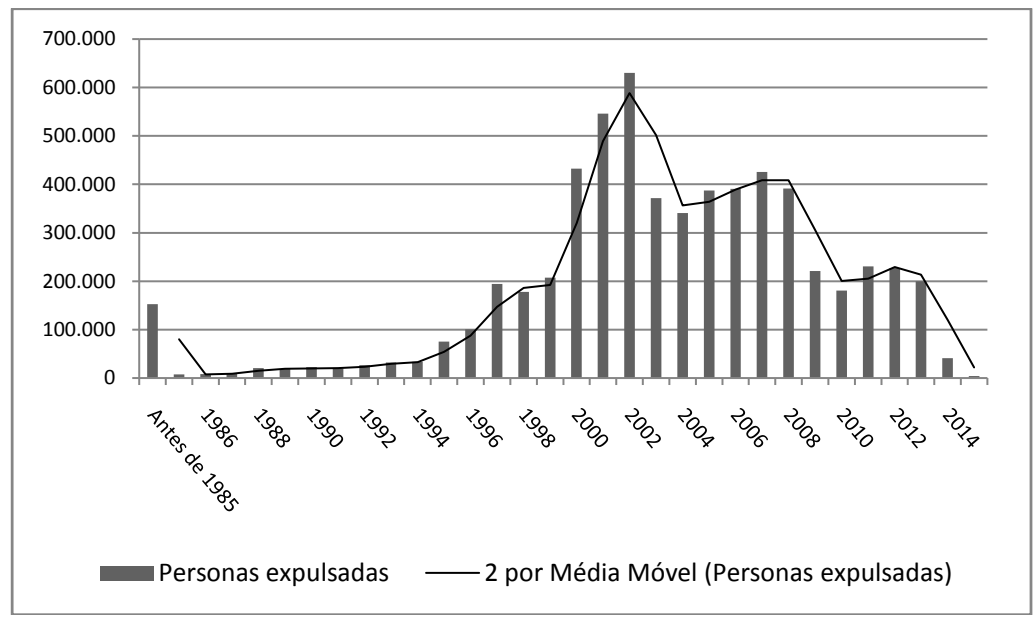

* Corte al 30 de abril de 2014. Elaboración Propia. Fuente. Registro Único de Victimas²5.

21 Ibidem, p. 7.

${ }^{22}$ El Decreto legislativo 11 de 1906 en sus artículos 2 y 3 entrega facultades al Presidente para que bajo Estado de Sitio imponga discrecionalmente penas de reclusión, prisión, "Confinamiento hasta por dos años; y Extrañamiento del territorio de la República hasta por cuatro años" y disponga que los procesados sean juzgados por "Tribunales ordinarios o la Corte Marcial o los Consejos de Guerra".

${ }^{23}$ BARRETO, Antonio. La generación del estado de sitio: el juicio a la anormalidad institucional colombiana en la Asamblea Nacional Constituyente de 1991. Rev. Precedente, v. I, julio-diciembre 2012. Universidad ICESI. Facultad de Derecho y Ciencias Sociales. Cali-Colombia.

24 ACNUR. Desplazamiento. El nuevo reto del siglo XXI. Tendencias Globales 2012. Ginebra, 2013.

${ }^{25}$ Disponible en: <http://rni.unidadvictimas.gov.co/?q=v-reportes>. Consultado: 20/08/2014. 
Los impactos del desplazamiento forzado interno se evidenciaron en cientos de poblados rurales deshabitados y la emergencia cotidiana de asentamientos en las periferias de las grandes urbes. Cabe destacar que si bien el desplazamiento forzado operó como parte de la lucha contrainsurgente, también accionó como mecanismo para el despojo en territorios considerados de importancia estratégica para la implementación de megaproyectos ${ }^{26}$.

Con la promulgación en el año 2002 del Decreto 2002 se revivieron los estados de excepción. Colombia volvería a estar bajo estado de sitio, se crean las denominadas Zonas de Rehabilitación y Consolidación, se restringen libertades individuales y se facultan a las fuerzas militares y de policía para proceder sin orden judicial ${ }^{27}$, cuando lo consideren necesario, en caso de detenciones o registro de inmuebles.

A partir de 2005, la persecución es dirigida a gran escala contra los opositores a la política de Seguridad Democrática ${ }^{28}$ declarados auxiliadores del terrorismo ${ }^{29}$. Las detenciones masivas ${ }^{30}$ y las ejecuciones extrajudiciales conocidas como falsos positivos ${ }^{31}$, ocuparon las tapas de los diarios nacionales. Los principales blancos de la represión fueron los defensores de derechos humanos, académicos y líderes sociales ${ }^{32}$. En consecuencia, el refugio de

${ }^{26}$ FAJARDO, El conflicto armado..., op. cit.

${ }^{27}$ Los artículos 14 y 15 del Decreto 2002 de 2002 establecen: ART 14. El derecho de circulación o residencia podrá limitarse, mediante medidas como el toque de queda, retenes militares, indicativos especiales para la movilización, permisos especiales para el libre tránsito, circulación o permanencia restringida o prohibida de personas o vehículos en horas y lugares determinados. ART 15. El Gobernador podrá, dentro del territorio de su jurisdicción, adoptar medidas para exigir a personas determinadas que comuniquen con una antelación de dos días, ante la primera autoridad civil del municipio y, en su defecto, ante el comandante de estación o subestación de Policía de la respectiva localidad, todo desplazamiento fuera de la misma cuando se trate de su residencia habitual.

${ }^{28}$ Política de gobierno de la Presidente de la Republica Álvaro Uribe V. (2002-2006/2006-2010).

29 Álvaro Uribe Vélez en su discurso de posesión como Presidente de la República pronunciado el 7 de agosto de 2002, Retomemos el lazo unificador de la ley, la autoridad democrática, la libertad y la justicia social, afirmó que: "cuando un Estado democrático es eficaz en sus garantías, así los logros sean progresivos, la violencia en su contra es terrorismo". Disponible en: < http://historico. presidencia.gov.co/discursos/discursos2002/agosto/discurso.htm>.

${ }^{30}$ El Presidente de la República en su discurso pronunciado en el LXIII Congreso Nacional Cafetero de diciembre de 2003 en afirmó que: "Al repasar el mapa cafetero de la Patria, hemos avanzado bastante en toda la ladera cundinamarquesa, tanto en la oriental como en la occidental. Persistiremos hasta desalojar de allí al último de los terroristas [...] La semana pasada le dije al General Castro Castro que en esa zona no podíamos seguir con capturas masivas de 40 o de 50 todos los domingos, sino de 200, para acelerar el encarcelamiento de los terroristas y golpear estas organizaciones". (Disponible en: <http://historico.presidencia.gov.co/discursos/discursos2003/ diciembre/congresocafetero.htm $>$ ).

${ }^{31}$ Los falsos positivos correspondió a una práctica de las fuerzas militares para mostrar resultados en la lucha contrainsurgente, alentada por el pago de recompensas con días de descanso, bonificaciones o reconocimiento militar. En el año 2007 la Mesa de Trabajo sobre ejecuciones extrajudiciales de la Coordinación Colombia-Europa-Estados Unidos documentó 3.796 casos.

32 Human Rights First, en su informe de febrero de 2009, afirma que "Tradicionalmente en Colombia 
colombianos apareció como un fenómeno masivo en Suramérica, tendencia que puede explicarse por el contexto político regional y las medidas migratorias adoptadas por distintos países de la región.

Roniger $^{33}$ afirma que tanto los gobiernos autoritarios como los democráticos utilizan la exclusión política por la vía del destierro, formal o no, y generan condiciones macro y micro sociales para que la ruta hacia el exilio sea contemplada por sus ciudadanos. En América Latina es posible constatar tal hipótesis con las dictaduras militares en las décadas entre 1960 y 1980, en el Cono Sur y Centroamérica, y en países bajo gobiernos elegidos democráticamente como Perú ${ }^{34}$, en la década de 1990, y Colombia, desde el inicio del conflicto interno. En ambos contextos la masiva violación de los derechos humanos, en medio de la persecución por la pertenencia a un grupo social o por las opiniones políticas, produjo una salida masiva de ciudadanos en búsqueda de refugio. En el caso colombiano se suma el ininterrumpido conflicto interno, de más de medio siglo, que persiste hasta hoy.

\section{Tras las huellas del refugio de colombianos}

El refugio es una figura legal, una tipificación propia del Derecho Internacional de los Derechos Humanos que reconoce un estado de excepción en el cual se encuentran determinadas personas que salen de sus países de nacionalidad o residencia. Esta figura tuvo su origen en una convención firmada en el período posterior a la Segunda Guerra Mundial y buscaba dar solución al masivo desplazamiento forzado sufrido en un área determinada del mundo, por lo que incluía una cláusula temporal y geográfica. Esta definición fue modificada hacia fines de la década del sesenta cuando la diplomacia internacional dio cuenta que los conflictos armados y las crisis humanitarias continuaban. Posteriormente, se amplió aún más a través de definiciones de naturaleza regional como la surgida en Cartagena en 1984. Ese hito a pesar que señalaba el nivel de conflictividad en los países de la región no fue de uso automático ni masivo. Una aparente paradoja nos muestra cómo esa definición acordada en Colombia, fue incorporada a la legislación nacional de este país recién en diciembre de 2013. En definitiva, al día de hoy, en todas las legislaciones

los funcionarios del estado y los paramilitares han presumido que los defensores son de la izquierda, y, por lo tanto, simpatizan con el movimiento guerrillero. Esta presunción ha producido una intensa persecución [...] en noviembre, 2008, un fiscal ordenó la inspección desproporcional de todas las bases de datos y libros de cinco universidades para encontrar pruebas de conexiones entre estudiantes, profesores y grupos subversivos" (HUMAN RIGHTS FIRST. Los defensores de derechos humanos acusados sin fundamento. Presos y señalados en Colombia. Washington D.C, 2009, p. 8-9).

33 RONIGER, op. cit.

${ }^{34}$ Sin embargo, en el caso de Perú cabe señalar el auto-golpe en 1992 del gobierno de Fujimori, al disolver el Congreso. 
nacionales suramericanas existen dos definiciones de quién es un refugiado. En primer lugar, la contemplada por la Convención de $1951^{35}$ y, por otro lado, la extendida por la Declaración de Cartagena ${ }^{36}$.

La mayoría de los elementos de análisis de las definiciones tienen ya una interpretación, una práctica y una jurisprudencia nacional e internacional; el uso o no de las mismas es atributo de los organismos nacionales de aplicación, que suelen estar dentro de los poderes ejecutivos. Sus decisiones deberían ser de carácter humanitario y no "político", en tanto no son una declaración diplomática de los gobiernos acerca de la naturaleza de la situación en los países expulsores.

Sobre la problemática de los refugiados y el asilo político en América del Sur, existe una vasta producción de análisis comparativo de la legislación y práctica jurídica desde la disciplina del Derecho Internacional Público, que trata sobre el sistema de protección que el Derecho Internacional del Refugiado consagra, así como de la tradición latinoamericana del asilo consagrada ya hacia fines del Siglo XIX ${ }^{37}$. En varios de estos $\operatorname{casos}^{38}$ el análisis ha quedado desactualizado por la dinámica modificación, en varios países latinoamericanos, en torno a las legislaciones sobre migración.

Volviendo sobre el caso colombiano, Guarnizo ${ }^{39}$ afirma que la emigración en este país empezó a ser registrada en la década del sesenta del siglo pasado, una vez terminado el período de La Violencia e iniciada la guerra actual, con tres destinos predominantes: Venezuela, Estados Unidos y Europa. La salida masiva del país coincide con la demanda de mano de obra en Venezuela a causa del boom petrolero y la asignación de cuotas migratorias con posibilidad de reunificación familiar por parte de los Estados Unidos. Este último destino sería

${ }^{35}$ La Convención de 1951 reconoce como refugiada a aquella persona que abriga fundados temores de ser perseguida por motivos de raza, religión, nacionalidad, pertenencia a determinado grupo social u opiniones políticas, se encuentre fuera del país de su nacionalidad y no pueda o no quiera acogerse a la protección de tal país.

${ }^{36}$ La Declaración de Cartagena amplia el reconocimiento como refugiados a aquellas personas que han huido de su país de nacionalidad o de residencia habitual porque su vida, seguridad o libertad han sido amenazadas por la violencia generalizada, la agresión extranjera, los conflictos internos, la violación masiva de los derechos humanos u otras circunstancias que hayan perturbado gravemente el orden público.

37 ARBOLEDA, Eduardo. El ACNUR, las migraciones internacionales y el derecho de asilo y refugio; CANÇADO TRINDADE, Antônio. Derecho Internacional de los Derechos Humanos, Derecho Internacional de los Refugiados y Derecho Internacional Humanitario: aproximaciones y convergencias; DUTRENIT BIELUZ, Silvia. Sobre la percepción y la decisión políticas de aplicar el asilo diplomático: una reflexión desde experiencias latinoamericanas; FRANCO, Leonardo (coord.). El asilo y la protección internacional de los refugiados en América Latina. Análisis crítico del dualismo "asilo-refugio" a la luz del derecho internacional de los derechos humanos; GALINDO, Francisco. El asilo en sistema de Naciones Unidas y en el sistema Interamericano.

${ }^{38}$ ARBOLETA, op. cit.; FRANCO et alii, op. cit.; GALINDO, op. cit.

${ }^{39}$ GUARNIZO, Luis Eduardo. La migración transnacional colombiana: Implicaciones teóricas y prácticas. 
el predilecto de las clases altas colombianas y, en menor grado, de comerciantes y medianos empresarios. Entre los años 1960 y 1980, Europa surgiría como destino de refugiados políticos de izquierda, intelectuales y artistas. Desde la década de 1990, con la implementación del modelo neoliberal, "[a]demás del deterioro económico, el país enfrentó el deterioro de su situación política, social y militar" ${ }^{\prime 40}$; la emigración, además de crecer en cifras, se hizo más heterogénea social y regionalmente, se dispersó en destinos y se generó la imagen de una suerte de diáspora colombiana.

La Organización Internacional para las Migraciones $(\mathrm{OIM})^{41}$ registraba hasta 1985 un millón y medio de colombianos viviendo en el exterior; veintitrés años después, se contabilizan 4.167.388 fuera del país, lo que equivale al 9\% de la población.

\section{Gráfica 2. Refugiados colombianos 1996-2013}

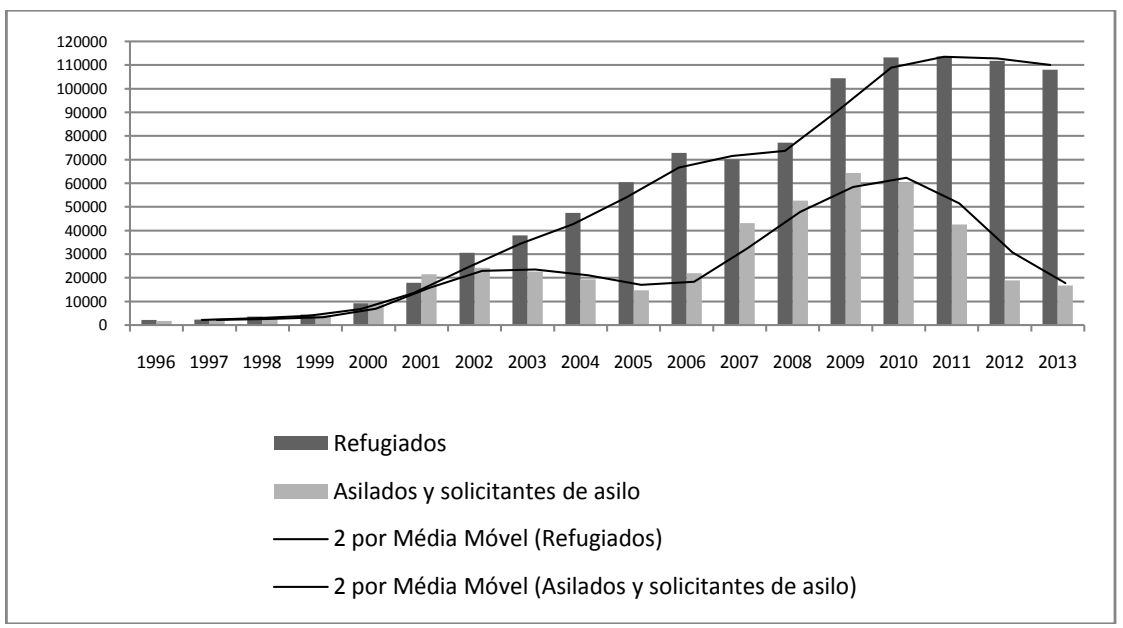

Elaboración propia.

Fuente ${ }^{42}$. ACNUR. Anuarios estadísticos 1996-2012. ACNUR, 2013; ACNUR. Tendencias Globales 2013. ACNUR, 2014.

El refugio mostró un incremento significativo a partir del año 2002, período que se caracteriza por la ruptura de los diálogos de paz entre el gobierno de Andrés Pastrana (1996-2002) y las FARC e implementación de la política de Seguridad Democrática (2002-2010). Como corolario, Colombia ocupa el octavo lugar a nivel mundial con mayor número de personas con el status de refugiado,

\footnotetext{
40 Ibidem, p. 26.

${ }^{41}$ Disponible en: <http://www.oim.org.co/migracion-colombiana/datos-sobre-migracion-colombia na.html>. Consultado: 22/08/2014.

42 Disponible en: <http://www.unhcr.org/pages/4a02afce6.html\#_ga=1.968818.2102483435.140 $8398443>$. Consultado: 22/08/2014.
} 
aunque se encuentra entre los veinte países con Índice de Reconocimiento Total para solicitantes de asilo más bajo. Entre quienes recurren a esta figura, tan solo el solo el $14 \%$ acceden a ella ${ }^{43}$. Cabe señalar que esta cifra no deja de ser una subestimación porque al haber crecido la emigración de colombianos, muchos que huyen del país con fundados temores de persecución y que consideran que su vida, seguridad o libertad corren peligro, no recurren a la figura del refugio por desinformación o temor.

La extensión de las redes migratorias colombianas y la apertura de la política migratoria en distintos países de la región (como Argentina) permiten que una persona con necesidades de protección internacional pueda establecerse sin necesidad de acudir al refugio u otras figuras humanitarias. Estados Unidos y Canadá continúan siendo países de destino de refugiados colombianos, probablemente, por las redes migratorias ya establecidas de larga data. Sin embargo, en la última década se ha registrado disminución de flujo hacia el norte del continente. Las políticas migratorias restrictivas y las medidas adoptadas desde 2001 tuvieron un evidente efecto. Ejemplos paradigmáticos son leyes aprobadas bajo la justificación de "interceptar" y "obstruir" el "terrorismo" como la Ley Patriota, Ley de Seguridad Contra el Terrorismo y Ley Antiterrorista. Europa, a su vez, se mantiene como un destino seguro para los refugiados, aunque desde la caída del muro de Berlín también disminuyó la entrada de personas en búsqueda de protección, lo que se le enmarca dentro de la denominada Crisis del Refugio ${ }^{44}$.

Hasta finales de la década de los noventa, Suramérica no figuraba como lugar de destino para los refugiados colombianos, probablemente por las condiciones políticas de los regímenes dictatoriales, particularmente en el Cono Sur. Aquella tradición de asilo latinoamericano, en la cual las fronteras eran espacios de circulación y exilio de contrincantes políticos de turno, se habían transformado con la instauración de la Doctrina de Seguridad Nacional. Las fronteras pasaron a ser un espacio vigilado donde los distintos Estados de América del Sur coordinaban tareas de persecución, captura y devolución de perseguidos políticos, tareas que fueron conocidas como el Plan Cóndor.

Sin embargo, esta situación cambió en la última década. Suramérica empieza a recibir refugiados colombianos, situación que coincide con el recrudecimiento del conflicto interno y el aumento del desplazamiento forzado. En los primeros años del nuevo siglo, se registraron desplazamientos masivos con cruce de fronteras en medio de fuertes operativos militares como "[l]a implementación del Plan Colombia I y Plan Patriota en los territorios del Sur

\footnotetext{
${ }^{43}$ ACNUR, Desplazamiento..., op. cit.

${ }^{44}$ RAMIREZ, Renzo. Sociedad, familia y género. El caso de los migrantes y exiliados colombianos en Suecia. Revista de estudios Sociales, n. 21, Bogotá- Colombia, Universidad de los Andes, 2005, p. 53-63.
} 
(frontera con Ecuador)" y "las políticas de seguridad aplicadas en las llamadas Zonas de Rehabilitación y Consolidación en Arauca (frontera con Venezuela)"45. La República Bolivariana de Venezuela (52\%) y Ecuador (32\%) se constituyen en los principales receptores de refugiados ${ }^{46}$.

La guerra colombiana había traspasado las fronteras, situación que conllevó momentos de tensión diplomática y ruptura de relaciones de los gobiernos de Ecuador y Venezuela con Colombia. Los países fronterizos se vieron obligados a declarar la emergencia humanitaria por la magnitud y los efectos del desplazamiento masivo de colombianos en busca de refugio. De los refugiados colombianos o personas que se encuentran en situación similar bajo protección el 18\% son menores de 18 años, el 13\% tiene más de 60 años y el 33\% del total son mujeres ${ }^{47}$. En el 2009 el 60\% de las nuevas solicitudes de refugio en el Cono Sur correspondían a colombianos, con un incremento anual mayor al 10\% ${ }^{48}$. La gran mayoría de los refugiados colombianos han salido del país en lo corrido del siglo XXI y se encuentran en Suramérica. La cercanía con los países fronterizos, las medidas migratorias adoptadas en la región, el contexto político alrededor de la unidad latinoamericana y la implementación del Plan de Acción de México $2004^{49}$ son algunas de las razones que pueden explicar esta tendencia.

Sin embargo, la cantidad de solicitudes y las posibilidades de acceder al status han ocasionado grandes cuellos de botella administrativos que potencian y generan la irregularidad migratoria. Como consecuencia de esto, surgieron programas como el Registro Ampliado en Ecuador, que permitieron acelerar y mejorar los procedimientos de reconocimiento de la condición de refugiado. Adicionalmente, existen registros de situaciones donde continuó la persecución a través de las fronteras, dando lugar a la necesidad urgente de reasentamiento, pero también, presionando a personas con pocos recursos para que emprendieran largos viajes para buscar protección en países más lejanos; entre los que aparecen Chile, Argentina, Uruguay y Brasil. Si bien este último es limítrofe con Colombia, la experiencia de esos espacios no tiene el mismo flujo

${ }^{45}$ Consultoría para los Derechos Humanos y el Desplazamiento. Colombia, Estados Unidos y los países vecinos frente al Desplazamiento forzado. Bogotá, 2004, p. 10.

${ }^{46}$ ACNUR, Desplazamiento..., op. cit.

47 Ibidem.

${ }^{48}$ ACNUR. Tendencias y desafíos de los refugiados y solicitantes de asilo en América Latina. Santiago de Chile, 2010. Disponible en: <http://www.cepal.org/celade/noticias/paginas/8/41138/ACNUR.pdf>.

${ }^{49}$ Plan de reasentamiento para refugiados colombianos surgido como salida a la crisis humanitaria declarada por los países fronterizos. El Plan México 2004 se compone de los programas: Ciudades Solidarias, Fronteras Solidarias y Reasentamiento Solidario. El programa de Reasentamiento Solidario que funciona en Ecuador sirvió para repartir levemente las cargas, entre los países de la región y descomprimir situaciones graves. 
continuo de personas como las fronteras con Ecuador y Venezuela, sin olvidar, además que la comunicación es por vía fluvial.

Tabla 1. Refugiados colombianos y peticionantes en Suramérica. 2007-2009

\begin{tabular}{|c|c|c|c|c|c|c|c|c|c|}
\hline \multirow{2}{*}{ País/Año } & \multicolumn{4}{|c|}{ Refugiados } & \multicolumn{4}{|c|}{ Solicitantes de Refugio } & \multirow{2}{*}{$\begin{array}{c}\text { Total } \\
\text { General }\end{array}$} \\
\hline & 2007 & 2008 & 2009 & Total & 2007 & 2008 & 2009 & Total & \\
\hline \multicolumn{10}{|l|}{ Sur América } \\
\hline Argentina & 152 & 179 & 381 & 712 & 123 & 171 & 129 & 423 & 1.135 \\
\hline Bolivia & 67 & 97 & 110 & 274 & 44 & 31 & 41 & 116 & 390 \\
\hline Brasil & 498 & 529 & 597 & 1.624 & 128 & 87 & 57 & 272 & 1.896 \\
\hline Chile & 948 & 1.061 & 874 & 2.883 & 713 & 816 & 403 & 1.932 & 4.815 \\
\hline Perú & 195 & 232 & 232 & 659 & 107 & 130 & 109 & 346 & 1.005 \\
\hline Ecuador & 1.4251 & 18.337 & 44.380 & 76.968 & 11.590 & 15.051 & 31.222 & 57.863 & 134.831 \\
\hline Venezuela & 843 & 1.094 & 1.244 & 3.181 & 2.335 & 2.920 & 2.860 & 8.115 & 11.296 \\
\hline Paraguay & 8 & 14 & 18 & 40 & 6 & 8 & 4 & 18 & 58 \\
\hline Uruguay & 49 & 49 & 68 & 166 & 12 & 1 & 34 & 47 & 213 \\
\hline Subtotal & 17.011 & 21.592 & 47.904 & 86.507 & 15.058 & 19.215 & 34.859 & 69.132 & 155.639 \\
\hline \multicolumn{10}{|l|}{$\begin{array}{l}\text { Otros países de } \\
\text { Latinoamérica }\end{array}$} \\
\hline Panamá & 1.284 & 1.303 & 1.299 & 3.886 & 328 & 176 & 187 & 691 & 4.577 \\
\hline Costa Rica & 9.739 & 9.939 & 10.199 & 29.877 & 752 & 735 & 799 & 2.286 & 32.163 \\
\hline México & 147 & 178 & 210 & 535 & 57 & 41 & 62 & 160 & 695 \\
\hline Subtotal & 11.170 & 11.420 & 11.708 & 34.298 & 1.137 & 952 & 1.048 & 3.137 & 37.435 \\
\hline Total General & 28.181 & 33.012 & 59.612 & 120.805 & 16.195 & 20.167 & 35.907 & 72.269 & 193.074 \\
\hline
\end{tabular}

Fuente: ACNUR50.

Entre los refugiados colombianos en América del Sur pueden considerarse por magnitud e impacto, en primer lugar, los que cruzan las fronteras limítrofes (asemejándose a las dinámicas del desplazamiento forzado interno), principalmente campesinos y personas de sectores populares. En segundo lugar, se encuentran perseguidos políticos propiamente dichos, en general opositores al régimen económico y político. Finalmente, están quienes ven amenazada su seguridad en el contexto del conflicto interno por pertenecer a sectores económicamente influyentes en el país y los que huyen de la violencia vinculada al narcotráfico o bandas criminales surgidas en el marco de la Ley de Justicia y Paz.

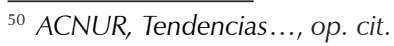




\section{A modo de reflexión. Los refugiados colombianos en el relato de la región}

Los regímenes dictatoriales en Suramérica pretendieron restablecer violentamente las continuidades de los proyectos políticos oligárquicos que fueron interrumpidos por expresiones políticas alternativas que se instalaban en el gobierno y el auge de los movimientos sociales. Mientras que en Colombia se aplicaron y se siguen aplicando las mismas prácticas represivas de las dictaduras militares latinoamericanas, sin la necesidad de modificar el sistema de gobierno dada la continuidad histórica de la oligarquía en el poder. En ambos casos se registra la sistemática violación a los derechos humanos que llevo a la masiva migración forzada.

Colombia es el único país en el continente con un éxodo sostenido durante los últimos treinta años por causa de la violencia política. A la fecha el 15\% de la población sufre el desplazamiento forzado interno, el $10 \%$ vive fuera del país y el $1 \%$ se encuentra bajo protección como refugiada o situaciones similares.

¿Quiénes son los refugiados? Son los cuerpos que sobreviven a matanzas, mutilaciones, cercenamientos o encierro. $\mathrm{Y}$, como tales, tienen en sus relatos y sobre sus espaldas la carga de estar alejados de su tierra, pero sobre todo de ser la prueba viviente de la guerra. Son relatos vivientes de una muerte, de un aniquilamiento y pesa sobre ellos el haber sobrevivido. Son excluidos políticos, al serles negado el derecho a la ciudadanía, expulsados de sus territorios, comunidades, colectivos y hogares. No quedará cerrada nunca su herida mientras no puedan decidir libremente retornar y permanecer en su país o lograr establecerse "estar" en el país que les protege.

¿Cuál es la paradoja de la situación del refugiado? Al ser reconocido como sujeto particular, como sujeto de derecho, por un Estado que le brinda una protección en virtud de su solicitud, por haber sido afectado por razones ajenas a su voluntad que lo obliga a salir de su país, parecería volver a los refugiados, en algún punto, sujetos visibles en los Estados de acogida, pero no lo son, en cuanto no se les reconoce como sujetos políticos, por la naturaleza misma del acto de reconocimiento, que en cuanto es un acto humanitario que reconoce un estado de excepción provisorio, no reconocerá la situación del país que lo expulsa. El Estado los reconoce como sujetos, pero carentes, sin voz política en el lugar de acogida, donde generalmente son percibidos como una amenaza por la población nativa, que no comprende como el acto de huir no debe ser visto más que como un acto de resistencia a un inminente aniquilamiento ${ }^{51}$.

\footnotetext{
${ }^{51}$ SEGATO, Rita. La escritura en el cuerpo de las mujeres asesinadas en Ciudad Juárez. Territorio, soberanía y crímenes de segundo Estado. México DF: Ed. De la Universidad del Claustro Sor Juana, Colección Voces, 2006.
} 
El refugio se vive bajo una fuerte tensión subjetiva que franquea tanto la vida pública como la privada. Aprender otro idioma, recalificarse para conseguir un trabajo, enfrentarse a otra cultura, siempre buscando similitudes y diferencias, necesitar amigos o descubrirse cada mañana escudriñando en los rincones de una geografía distinta para encontrar lugares que recreen sus viejos caminos; es como renunciar a su historia y su pasado. Integrarse a la sociedad de acogida requiere de grandes esfuerzos y rupturas subjetivas significativas, pues integrarse es como renunciar a "volver" a su paîs ${ }^{52}$. Pero, además, los refugiados colombianos, al igual que los migrantes, se enfrentan al estigma del narcotráfico.

Ahora bien, la reconstrucción del discurso que los niega da cuenta de que los discursos no sólo esconden u obliteran relaciones de dominación, sino que también las construyen, las reproducen y las materializan. Esto no significa que el poder de las ideas sea mayor al de la realidad misma. Sino que los discursos forman parte de las realidades y se vuelven materiales en la vida cotidiana, en la historia "exilio, inmigración y cruce de las barreras son experiencias que pueden proporcionarnos nuevas formas narrativas, otras formas de contar" ${ }^{\prime 53}$. En consecuencia, recuperar el lugar que tienen los refugiados, para Colombia, puede significar romper con la monoglosia que representa el discurso de la estatalidad, que se puede caracterizar como la unicidad del discurso de la autoridad del país expulsor que justifica los desplazamientos, la violencia y la muerte, como parte de un orden que se debe sostener y reproducir y cuyos daños colaterales, en última instancia, son la mutilación, el encierro o aislamiento, la muerte y el refugio. En otras palabras, los refugiados pueden ser vistos como el relato de un aniquilamiento, en su doble acepción, en sentido físico y cultural, que funcionan como una supervivencia y cuyas narraciones pueden ayudar a reconstruir, sino reformular, la historia escrita desde el poder que ahoga otros relatos.

Su realidad parece ser aquella de los que no tienen voz en sus lugares de origen, más bien que sus voces son inaudibles. Esto no quiere decir que salgan de su lugar de subalternidad, de opresión, pero sí que potencialmente recuperen un lugar de enunciación reconocido por el Estado que los recibe y protege. Son reconocidos como "condenados" y por esto el Estado les reconoce una serie de derechos. En consecuencia, los Estados deben respetar su derecho a la supervivencia, como individuos y como comunidades.

Más del $80 \%$ de los refugiados colombianos se encuentran hoy en América del Sur, dando cuenta de una región que no está en paz. Hoy Colombia se encuentra nuevamente en medio de diálogos de paz entre el Estado y las

\footnotetext{
${ }^{52}$ MERKLEN, Denis. Sufrir lejos, quedarse juntos. El exilio de los uruguayos en Francia.

${ }^{53}$ SAID, Edward. Representar al colonizado. Los interlocutores de la antropología. In GONZÁLEZ STEPHAN, Beatriz (ed.). Cultura y Tercer Mundo. Cambios en el saber académico. Tomo 1, Caracas: Nueva Sociedad, 1996, p. 58.
} 
FARC. En las últimas elecciones un gran porcentaje de los votantes eligieron un candidato a presidente que sugería volver a la política de seguridad que generó más desplazados y refugiados en los últimos treinta años. Sin embargo, más allá de lo que pueda suceder con las negociaciones de paz, Colombia está lejos de ser un país donde pronto la violencia deje de ser medular y estructural. Tal como afirma ACNUR ${ }^{54}$, la acción humanitaria para los refugiados y la población desplazada interna no puede limitarse únicamente a la ayuda de emergencia, sino que también debe centrarse en las soluciones duraderas que significan invertir en la consolidación de la paz.

\section{Bibliografía}

AMBROSO, Guido. Nuevos temas en la investigación sobre refugiados. Ginebra: ACNUR, Oficina de evaluación de programas. Informe de Investigación 207, 2011. ARBOLEDA, Eduardo. El ACNUR, las migraciones internacionales y el derecho de asilo y refugio. Revista Mexicana de Política Exterior, Instituto Mauas Romero de Estudios Diplomáticos, México, 1994.

CANÇADO TRINDADE, Antônio. Derecho Internacional de los Derechos Humanos, Derecho Internacional de los Refugiados y Derecho Internacional Humanitario: aproximaciones y convergencias. In 10 años de la Declaración de Cartagena sobre Refugiados: Memoria Coloquio Internacional IIDH-ACNUR. San José de Costa Rica, 1995.

DUTRENIT BIELUZ, Silvia. Sobre la percepción y la decisión políticas de aplicar el asilo diplomático: una reflexión desde experiencias latinoamericanas. Revista América Latina Hoy, n. 22, Universidad de Salamanca, España, 1999.

FRANCO, Marina. El exilio. Argentinos en Francia durante la dictadura. Argentina: Siglo XXI Editores, 2008.

FRANCO, Leonardo (coord.). El asilo y la protección internacional de los refugiados en América Latina. Análisis crítico del dualismo "asilo-refugio" a la luz del derecho internacional de los derechos humanos. Buenos Aires: UNLA/ACNUR/Siglo XXI, 2003.

GALINDO, Francisco. El asilo en sistema de Naciones Unidas y en el sistema Interamericano. In Compilación de instrumentos jurídicos regionales relativos a Derechos Humanos, refugiados y asilo, 2003.

GONZALEZ, Pilar. Emigrar en tiempos de crisis al país de los derechos humanos. In Anuario de Estudios Americanos, 2007.

GUARNIZO, Luis Eduardo. La migración transnacional colombiana: Implicaciones teóricas y prácticas. Memorias. Seminario sobre migración internacional colombiana y la conformación de comunidades transnacionales. Bogotá: Programa Colombia Nos Une/Ministerio de Relaciones Exteriores de Colombia, 2003.

\footnotetext{
${ }^{54}$ Alto Comisionado para Los Refugiados. En los zapatos de los refugiados: Ofrecer protección y soluciones a los desplazados colombianos en Ecuador. Washington: ACNUR, 2011.
} 
MERKLEN, Denis. Sufrir lejos, quedarse juntos. El exilio de los uruguayos en Francia. Anuario de Estudios Americanos, Sevilla - España, p. 63-86, 2007.

RONIGER, Luis. Exilio, ciudadanía y teoría socio-política. In Políticas del exilio. Orígenes y vigencia de un concepto. Buenos Aires: EDUNTREF, 2012, p. 197-208. ZOLBERG et alii. Escape from violence: Conflict and the refugee crisis in developing Word. New York. Oxford, 1989.

\section{Abstract}

\section{South America and the Colombian refugees}

Thirty years after the Declaration of Cartagena, in a region considered peaceful, the daily facts show a different reality. In Colombia, a democratic country located in northwestern South America, the civil war has crossed national borders and state violence is similar to that applied by the military governments in the Southern Cone. Among other records of massive and systematic violation of human rights, more than five million are internally displaced and nearly half a million refugees are an example. Banishment used as a mechanism of political exclusion, begins to be visualized due the magnitude of the exodus. The reconstruction of a discourse that denies them shows that this exclusion not only conceals or obliterates relations of domination, but also build, reproduce and materialize them. Who are the refugees? Where do they go for protection? What place are they given in the countries that protect them? These are some of the questions addressed in this article.

Keywords: human rights, forced internal displacement, refugee, Colombia, South America.

Recebido para publicación en 28/08/2014.

Aceptado para publicación en 29/10/2014.

Received for publication in August, 28 ${ }^{\text {th }}, 2014$. Accepted for publication in October, 29 ${ }^{\text {th }}, 2014$. 